\title{
Kindergarten Teacher Professionalism In Designing Learning (Study From Home) During Covid-19
}

\author{
Fefi Andrayani, Asdi Wirman
}

Received: 30062021 / Accepted: 25062021 / Published online: 30062021

(C) 2021 Association of Indonesian Islamic Early Childhood Education Study Program

\begin{abstract}
Abstrak Penelitian ini dilatarbelakangi keraguan guru dalam mendesain pembelajaran BDR di Inderapura Kabupaten Pesisir Selatan. Penelitian ini bertujuan mengetahui "Profesionalisme Guru Taman Kanak-kanak dalam Mendesain Pembelajaran BDR (Belajar Dari Rumah) selama Covid-19. Jenis penelitian ini deskriptif kuantitatif pendekatan ex post facto, populasi penelitian berjumlah 81 orang, sampel berjumlah 45 orang menggunakan teknik purposive sampling. Instrumen penelitian menggunakan angket model skala likert. Analisis data penelitian diperoleh melalui hasil kuesioner dengan analisis deskriptif menggunakan persentase. Diperoleh hasil bahwa profesionalisme guru TK dalam mendesain pembelajaran BDR selama Covid-19 dilihat dari subvariabel rancangan pembelajaran BDR sebanyak 54\% responden memilih jawaban selalu (SL), rancangan mekanisme pelaksanaan pembelajaran $44 \%$ jawaban selalu (SL), dan rancangan penilaian pembelajaran BDR 49\% jawaban selalu (SL). Berdasarkan data tersebut, disimpulkan bahwa profesionalisme guru TK dalam mendesain pembelajaran BDR dilihat dari rancangan pembelajaran, rancangan mekanisme pembelajaran, dan rancangan penilaian pembelajaran BDR di Inderapura Kabupaten Pesisir Selatan terlihat baik.
\end{abstract}

Kata Kunci: Profesionalisme guru TK, Desain Pembelajaran BDR, Covid-19

\begin{abstract}
This research was motivated by the teacher's doubts in designing BDR learning in Inderapura, Pesisir Selatan Regency. This study aims to determine the "Professionalism of Kindergarten Teachers in Designing BDR Learning (Learning From Home) during Covid19). This type of research is descriptive quantitative ex post facto approach, the study population amounted to 81 people, a sample of 45 people using purposive sampling technique. The research instrument used a Likert scale model questionnaire. Analysis of research data obtained through the results of a questionnaire with descriptive analysis using percentages. The results showed that the professionalism of kindergarten teachers in designing BDR learning during Covid-19 was seen from the BDR learning design subvariable as many as $54 \%$ of respondents chose always answers (SL), the design of the learning implementation mechanism 44\% always answered (SL), and the BDR learning assessment design 49\% the answer is always (SL). Based on these data, it is concluded that the professionalism of kindergarten teachers in designing BDR learning is seen from the learning design, the learning mechanism design, and the BDR learning assessment design in Inderapura, Pesisir Selatan Regency looks good.
\end{abstract}

Keywords: Kindergarten teacher professionalism, BDR Learning Design, Covid-19

\section{Pendahuluan}

Pendidikan merupakan upaya untuk membantu jiwa anak-anak didik baik lahir maupun batin, dari sifat kodratnya menuju ke arah peradaban manusiawi (Sujana, 2019: 29) Pendidikan merupakan suatu usaha yang dilakukan untuk membangun kepribadian seseorang 
agar siap dalam menghadapi kehidupan di masa mendatang, dengan demikian pendidikan sangat dibutuhkan bagi kehidupan manusia. Melalui pendidikan potensi dan kemampuan seseorang dapat dibentuk sehingga berguna bagi kehidupannya. Menurut (Juandi, 2019) pendidikan merupakan kiat dalam menerapkan prinsip-prinsip ilmu pengetahuan dan teknologi bagi pembentukan manusia seutuhnya. Berdasarkan beberapa pendapat tersebut dapat disimpulkan bahwa, pendidikan merupakan bentuk upaya pemberian stimulasi yang bertujuan agar anak dapat berkembang sesuai tahapan perkembangan dan mampu beradaptasi dengan lingkungannya.

Sesuai dengan tujuan pendidikan nasioanal Indonesia berdasarkan Undang- Undang No. 20 Tahun 2003 yaitu, pendidikan diupayakan dengan berawal dari manusia apa adanya (aktualisasi) dengan mempertimbangkan berbagai kemungkinan yang apa adanya (potensialitas), dan diarahkan menuju terwujudnya manusia yang seharusnya atau manusia yang dicita-citakan (idealistis). Tujuan pendidikan itu tiada lain adalah mengembangkan potensi peserta didik agar menjadi manusia yang beriman dan bertakwa kepada Tuhan Yang Maha Esa, berakhlak mulia, sehat, berilmu, cakap, kreatif, mandiri, dan menjadi warga negara yang demokratis serta bertanggung jawab (Sujana, 2019: 31). Oleh sebab itu pendidikan idealnya dimulai dari pendidikan sejak dini.

Demi terselenggarakannya suatu pendidikan diperlukan tenaga pendidik yang kompeten dibidangnya. Adapun kompetensi guru merupakan perpaduan antara kemampuan personal, keilmuan, teknologi, sosial, dan spiritual yang secara kaffah membentuk kompetensi standar profesi guru, yang mencakup penguasaan materi, pemahaman terhadap peserta didik, pembelajaran yang mendidik, pengembangan pribadi dan profesionalisme (Rasmita, 2019: 561). Kompetensi yang mesti dimiliki oleh seorang guru meliputi 4 kompetensi yaitu, kompetensi pedagogik, kepribadian, sosial dan profesional. Keempat kompetensi tersebut saling keterkaitan satu sama lain agar terbentuknya guru yang profesional. Kompentensi tersebut sangat berpengaruh terhadap kualitas seorang guru dalam proses belajar mengajar, maka empat kompetensi tersebut harus dimiliki oleh setiap tenaga pendidik.

Sebagaimana yang dimaksud dalam Permendikbud Nomor 137 Tahun 2014 Bab VII Pasal 24 Ayat 1 tentang tenaga pendidik yiatu "tenaga profesional yang bertugas merancang, mengimplementasi dan mengevaluasi hasil pembelajaran, serta melakukan pengasahan, pengasihan, dan pengasuhan dan penjagaan" (Dista, 2020: 106). Berdasarkan maksud dari Permendikbud tersebut guru PAUD dituntut kreatif dalam berlangsungnya proses pembelajaran. Guru PAUD dituntut mampu membuat rencana pembelajaran yang sesuai dengan standar tingkat pencapaian perkembangan anak.

Mengacu dari beberapa ulasan mengenai ketentuan dalam pendidikan anak usia dini tersebut, dapat disimpulkan bahwa kompetensi yang dimiliki pendidik, kualifikasi pendidik itu sendiri serta kemampuan seorang pendidik dalam mengelola sistem pembelajaran mencerminkan keprofesionalan seorang pendidik dalam proses pembelajaran. Oleh sebab itu masih terdapat banyak keraguan para guru dalam mendesain pembelajaran. Hal itu berupa dari segi merancang rencana, merancanag mekanisme pelaksanaan dan rancangan penilaian pembelajaran BDR, hasil wawancara dan observasi ditemukan adanya ketidaksesuaian antara rencana pelaksanaan pembelajaran harian dengan implementasi pada saat proses belajar BDR.

\section{Metode}

Penelitian ini menggunakan metode deskriptif kuantitaif dengan pendekatan penelitian ex post facto. Dengan jumlah populasi sebanyak 81 orang dan sampel berjumlah 45 orang. Instrument penelitian ini menggunakan kuesioner. Data yang dikumpulkan kemudian dianalisis secara deskriptif yaitu frekuensi dan persentase. 


\section{Hasil Penelitian}

Tabel 1. Rancangan pembelajaran BDR

\begin{tabular}{|c|c|c|c|c|c|c|c|c|c|c|}
\hline \multirow{3}{*}{ Item } & \multicolumn{10}{|c|}{ Alternatif Jawaban } \\
\hline & \multicolumn{2}{|c|}{ SL } & \multicolumn{2}{|c|}{ SR } & \multicolumn{2}{|c|}{ KD } & \multicolumn{2}{|c|}{ JR } & \multicolumn{2}{|c|}{ TP } \\
\hline & $\mathrm{Fi}$ & $\%$ & $\mathrm{Fi}$ & $\%$ & $\mathrm{Fi}$ & $\%$ & $\mathrm{Fi}$ & $\%$ & $\mathrm{Fi}$ & $\%$ \\
\hline A1 & 32 & 71 & 12 & 27 & 1 & 2 & 0 & 0 & 0 & 0 \\
\hline $\mathrm{A} 2$ & 26 & 58 & 9 & 20 & 9 & 20 & 1 & 2 & 0 & 0 \\
\hline A3 & 27 & 60 & 15 & 33 & 3 & 7 & 0 & 0 & 0 & 0 \\
\hline A4 & 24 & 53 & 10 & 22 & 10 & 22 & 1 & 2 & 0 & 0 \\
\hline A5 & 24 & 53 & 15 & 33 & 6 & 13 & 0 & 0 & 0 & 0 \\
\hline A6 & 25 & 56 & 15 & 33 & 5 & 11 & 0 & 0 & 0 & 0 \\
\hline A7 & 23 & 51 & 9 & 20 & 12 & 27 & 1 & 2 & 0 & 0 \\
\hline A8 & 25 & 56 & 10 & 22 & 10 & 22 & 0 & 0 & 0 & 0 \\
\hline A9 & 23 & 51 & 10 & 22 & 12 & 27 & 0 & 0 & 0 & 0 \\
\hline A10 & 15 & 33 & 21 & 47 & 7 & 16 & 2 & 4 & 0 & 0 \\
\hline $\mathrm{N}$ & & 542 & & 280 & & 167 & & 11 & & 0 \\
\hline $\begin{array}{c}\text { Rata- } \\
\text { rata }\end{array}$ & & 54 & & 28 & & 17 & & 1 & & 0 \\
\hline
\end{tabular}

Keterangan:

$\mathrm{A} 1=$ Mengidentifikasi tujuan umum pembelajaran ketika mendesain rencana pelaksanaan pembelajaran BDR

A2 = Menyusun tujuan pembelajaran BDR berdasarkan kemampuan anak

A3 = Mengidentifikasi tujuan umum pembelajaran berpedoman pada kurikulum PAUD

A4= Menyusun materi pembelajaran menyesuaikan tema dengan karakteristik anak

A5 = Menyusun materi pembelajaran BDR menyesuaikan dengan KD (kompetensi dasar) pada kurikulum PAUD

A6= Mengembangkan materi pembelajaran sesuai dengan tujuan pembelajaran BDR yang akan dicapai

$\mathrm{A} 7=$ Penggunaan pendekatan pembelajaran dilihat dari merancang materi pembelajaran yang mampu diaplikasikan orang tua dan anak

A8 $=$ Penggunaan metode pembelajaran dan menjelaskan setiap langkah proses pembelajaran BDR kepada wali murid

A9 $=$ Menentukan metode setiap kegiatan pembelajaran BDR

$\mathrm{A} 10=$ Penggunaan media pembelajaran yang sesuai dengan tujuan pembelajaran BDR yang ingin dicapai

Berdasarkan tabel tersebut diperoleh sebanyak 54\% memilih alternatif jawaban selalu (SL), 28\% memilih alternatif jawaban sering (SR), 17\% memilih alternatif jawaban kadangkadang (KD), $1 \%$ memilih alternatif jawaban jarang (JR), dan $0 \%$ responden yang memilih alternatif jawaban tidak pernah.

Tabel 2. Rancangan mekanisme pelaksanaan pembelajaran BDR

\begin{tabular}{|c|c|c|c|c|c|c|c|c|c|c|}
\hline \multirow{3}{*}{ Item } & \multicolumn{10}{|c|}{ Alternatif Jawaban } \\
\hline & \multicolumn{2}{|c|}{ SL } & \multicolumn{2}{|c|}{ SR } & \multicolumn{2}{|c|}{ KD } & \multicolumn{2}{|c|}{ JR } & \multicolumn{2}{|c|}{ TP } \\
\hline & $\mathrm{Fi}$ & $\%$ & $\mathrm{Fi}$ & $\%$ & $\mathrm{Fi}$ & $\%$ & $\mathrm{Fi}$ & $\%$ & $\mathrm{Fi}$ & $\%$ \\
\hline A1 & 16 & 36 & 18 & 40 & 9 & 20 & 1 & 2 & 1 & 2 \\
\hline $\mathrm{A} 2$ & 21 & 47 & 15 & & 8 & 18 & 1 & 2 & 0 & 0 \\
\hline A3 & 17 & 38 & 20 & 44 & 8 & 18 & & 0 & 0 & 0 \\
\hline A4 & 21 & 47 & 13 & 29 & 8 & 18 & 2 & 4 & 1 & 2 \\
\hline A5 & 21 & 47 & 10 & 22 & 12 & 27 & 2 & 4 & 0 & 0 \\
\hline A6 & 17 & 38 & 18 & 40 & 9 & 20 & 0 & 0 & 1 & 2,22 \\
\hline A7 & 27 & 60 & 7 & 16 & 11 & 24 & 0 & 0 & 0 & 0 \\
\hline $\mathrm{N}$ & & 311 & & 191 & & 144 & & 13 & & 7 \\
\hline Rata-rata & & 44 & & 27 & & 21 & & 1,9 & & 0,95 \\
\hline
\end{tabular}


Keterangan:

A1 $=$ Pengelolaan pelaksanaan pembelajaran dengan menentukan cara pengorganisasian yang mengkondisikan anak berpartisipasi aktif dalam pembelajaran BDR

$\mathrm{A} 2=$ Pengelolaan pelaksanaan pembelajaran dengan menyusun tujuan pembelajaran BDR berdasarkan kemampuan anak

$\mathrm{A} 3=$ Proses pembelajaran komunikatif menyusun kegiatan pembelajaran BDR yang dapat mengembangkan ekspresi lisan anak

A4 $=$ Proses pembelajaran komunikatif dengan merancang kegiatan pembelajaran BDR yang dapat mengembangkan ekspresi tulisan anak

A5 $=$ Proses pembelajaran komunikatif menentukan suatu kegiatan yang dapat memicu anak mengekpresikan dirinya

A6 $=$ Aktivitas pembelajaran peserta didik merancang kegiatan bermain yang dapat menimbulkan pengetahuan baru bagi anak

$\mathrm{A} 7=$ Saya menyediakan alat bantu pembelajaran seperti (kertas, pensil, pewarna dan perlengkapan lainnya) sebagai penunjang proses BDR

Berdasarkan tabel diatas menunjukkan bahwa sebanyak $44 \%$ memilih alternatif jawaban selalu (SL), 27\% memilih jawaban sering (SR), 21\% memilih jawaban kadang-kadang (KD), 1,9\% memilih jawaban jarang (JR), dan 0,95 memilih alternatif jawaban tidak pernah (TP).

Tabel 3. Rancangan penilaian pembelajaran BDR

\begin{tabular}{|c|c|c|c|c|c|c|c|c|c|c|}
\hline \multirow{3}{*}{ Item } & \multicolumn{10}{|c|}{ Alternatif Jawaban } \\
\hline & \multicolumn{2}{|c|}{ SL } & \multicolumn{2}{|c|}{ SR } & \multicolumn{2}{|c|}{ KD } & \multicolumn{2}{|c|}{ JR } & \multicolumn{2}{|c|}{ TP } \\
\hline & $\mathrm{Fi}$ & $\%$ & $\mathrm{Fi}$ & $\%$ & Fi & $\%$ & $\mathrm{Fi}$ & $\%$ & $\mathrm{Fi}$ & $\%$ \\
\hline A1 & 29 & 64 & 14 & 31 & 2 & 4 & 0 & 0 & 0 & 0 \\
\hline A2 & 25 & 56 & 11 & 24 & 9 & 20 & 0 & 0 & 0 & 0 \\
\hline A3 & 20 & 44 & 15 & 33 & 9 & 20 & 1 & 2 & 0 & 0 \\
\hline A4 & 19 & 42 & 18 & 40 & 8 & 18 & 0 & 0 & 0 & 0 \\
\hline A5 & 23 & 51 & 17 & 38 & 4 & 9 & 1 & 2 & 0 & 0 \\
\hline A6 & 18 & 40 & 22 & 49 & 5 & 11 & 0 & 0 & 0 & 0 \\
\hline A7 & 19 & 42 & 15 & 33 & 10 & 22 & 1 & 2 & 0 & 0 \\
\hline $\mathrm{N}$ & & 340 & & 249 & & 104 & & 6,67 & & $\mathbf{0}$ \\
\hline $\begin{array}{l}\text { Rata- } \\
\text { rata }\end{array}$ & & 49 & & 36 & & 15 & & $\mathbf{0 , 9 5}$ & & $\mathbf{0}$ \\
\hline
\end{tabular}

Keterangan:

$\mathrm{A} 1=$ Anak dinilai berdasarkan kurikulum apa yang dipelajari dan yang dikerjakan dengan menyusun instrument penilaian pembelajaran BDR yang berpedoman pada kurikulum PAUD

A2= Anak dinilai berdasarkan kurikulum apa yang dipelajari dan yang dikerjakan dengan mengembangkan instrument penilaian pembelajaran untuk mengukur aspek perkembangan anak

A3= Penilaian yang kooperatif dan kolaboratif menentukan format penilaian pembelajaran BDR untuk mengukur aspek perkembangan anak

A4= Menilai anak secara menyeluruh mengumpulkan dokumentasi berupa foto proses pembelajaran

A5= Menilai anak secara menyeluruh dengan mengumpulkan hasil karya anak selama pembelajaran

A6 = Menilai anak dan karya mereka dengan membuat hasil capaian pembelajaran BDR sebagai bentuk laporan perkembangan anak

A7 = Menilai anak dan karya mereka dengan membuat rancangan evaluasi tahapan pencapaian perkembangan anak selama BDR

Berdasarkan tabel tersebut menunjukkan bahwa sebanyak $46 \%$ responden memilih alternatif jawaban selalu (SL), 36\% memilih alternatif jawaban sering (SR), 15\% memilih 
alternatif jawaban kadang-kadang (KD), 0,95\% memilih jawaban jarang (JR) dan 0\% memilih jawaban tidak penah (TP)

\section{Pembahasan}

Hasil kuesioner menunjukkan secara umum bahwa guru taman Kanak-kanak merancang rencana pembelajaran pada saat pembelajaran BDR. Hasil penelitian ini didukung oleh pernyataan (Salim et al., 2020: 98) secara implisit dalam pembelajaran terdapat kegiatan memilih, menetapkan, mengembangkan metode untuk mencapai hasil pembelajaran yang diinginkan. Kegiatan-kegiatan tersebut pada dasarnya merupakan inti dari rancangan pembelajaran. Dalam rancangan pembelajaran terdapat beberapa item yang mesti ada didalamnya berupa daftar judul pelajaran dan urutannya akan tersusun secara runtut sehingga merupakan suatu program. Dalam rancangan pembelajaran tercantum segala sesuatu yang akan dilakukan untuk mendidik anak dan yang berhubungan erat dengan pendidikan tersebut (Gina, Syarif, Nasir, \& Perdhana, 2020: 69).

Dikuatkan oleh pernyataan (Dewiastri \& Mulyana, 2020) komponen rancangan rencana kegiatan pembelajaran meliputi bahan, alat, media, petunjuk, dan pedoman yang akan digunakan dalam proses pembelajaran. Rancangan rencana kegiatan pembelajaran ini merupakan acuan untuk guru dalam melaksanakan pembelajaran setiap harinya, sehingga penting bagi seorang pengajar menuangkan rancangan pembelajaran yang sistematis sesuai langkah ilmiah dalam rancangan pelaksanaan pembelajaran harian.

Selanjutnya secara umum merancang mekanisme pelaksanaan pembelajaran BDR hal tersebut terlihat dari banyaknya responden yang memilih alternatif jawaban selalu. Sejalan dengan pendapat (Nastita, 2019) menjelasakan bahwa kegiatan pembelajaran membutuhkan sebuah desain pembelajaran yang menentukan peta perjalanan dan tujuan akhir dari sebuah pembelajaran. Rencana pelaksanaan pembelajaran merupakan rancangan bagi guru untuk melaksanakan kegiatan bermain yang memfasilitasi anak dalam proses belajar. Rencana pelaksanaan pembelajaran dibuat sebelum kegiatan pembelajaran dilaksanakan. Rencana pembelajaran harus mengacu kepada karakteristik (usia, sosial budaya, dan kebutuhan individual) anak. Pembelajaran akan berjalan sesuai dengan rencana jika pembelajaran diarahkan sesuai dengan perencanaan yang sudah dibuat sebelumnya, sehingga tujuan pembelajaran yang sudah dirumuskan dapat tercapai.

Sejalan dengan pernyataan (Khayya, 2020: 21) berpendapat bahwa persyaratan kemampuan yang harus dimiliki guru dalam melaksanakan proses belajar mengajar meliputi kemampuan: 1) menggunakan metode belajar, media pelajaran, dan bahan latihan yang sesuai dengan tujuan pelajaran; 2) mendemonstrasikan penguasaan mata pelajaran dan perlengkapan pengajaran; 3) berkomunikasi dengan siswa; 4) mendemonstrasikan berbagai metode mengajar; dan 5) melaksanakan evaluasi proses belajar mengajar.

Berdasarkan hasil kuesioner tersebut menunjukkan bahwa guru taman-kanak membuat rancangan penilaian pembelajaran BDR terlihat dari banyaknya responden yang memilih alternatif jawaban selalu. Sejalan dengan penyataan Menurut (Haryono \& Hadiwinarto, 2020: 31-32) guru sebagai penilai pembelajaran berarti guru bertugas untuk menilai perkembangan anak dalam belajar. Tujuan diadakannya penilaian adalah untuk mengetahui ketercapaian tujuan pembelajaran yang telah ditentukan. Guna mencapai tujuan tersebut maka guru menggunakan instrumen penilaian untuk melakukan penilaian. Standar peniliain merupakan kegiatan penilaian yang dilakukan oleh pendidik dengan menggunakan acuan/instrument penilaian pada saat melakukan proses dan hasil belajar sesuai dengan standar tingkat pencapaian perkembangan usia anak.

Penilaian yang dilakukan terhadap proses belajar mengajar pada umumnya berfungsi sebagai untuk mengetahui tercapai tidaknya tujuan pengajaran, untuk mengetahui keefektifan proses belajar mengajar yang telah dilakukan oleh guru. Dalam melakukan penilaian ada beberapa pedoman yang harus diperhatikan pedoman penilaian hasil belajar ini diperuntukan bagi : 1) anak usia 4-6 tahun sebagai acuan dalam referensi yang di pertimbangkan proses dan 
hasil belajar; 2) anak usia lahir - 4 tahun sebagai referensi yang dipertimbangkan dalam melaksanakan penilaian stimulasi tumbuh kembang anak; dan 3) anak sebagai acuan dalam merancang dan memantau pelaksanaan penilaian proses dan hasil belajar (Praticia, Kamala, \& Juliawati, 2019: 50-51). Menurut (Sari, 2020: 38) menjeslakan terdapat beberapa prinsip penilaian dalam pembelajaran anak usia dini diantaranya mendidik, berkesinabungan, objektif, akuntabel, transparan, sistematis, menyeluruh, dan bermakna.

\section{Simpulan dan Saran}

Hasil analisis kuesioner menunjukkan bahwa profesionalisme guru taman Kanakkanak dalam mendesain pembelajaran BDR selama pandemi covid-19 di Inderapura Kabupaten Pesisir Selatan dilihat dari rancangan pembelajaran, rancangan mekanisme pelaksanaan pembelajaran BDR, rancangan penilaian pembelajaran BDR terlihat baik yaitu guru selalu memperhatikan tujuan pembelajaran yang ingin dicapai, guru memperhatikan pembelajaran yang sesuai agar perkembangan anak dapat berkembang sesuai dengan yang diharapkan. Namun terdapat beberapa guru yang masih belum memperhatikan bagaimana dalam mendesain pembelajaran agar tercapainya tujuan yang di inginkan. Oleh karena itu perlu ditingkatkan kompetensi setiap pendidik agar dalam melaksanakan proses pembelajaran menjadi tenaga profesional, bagi kepala sekolah, pengawas dan kementerian pendidikan dapat menjadikan hasil kajian ini sebagai langkah dalam mengambil tindakan terhadap persoalan yang ditemukan di lapangan dalam penelitian tersebut

\section{Daftar Rujukan}

Dewiastri, A. R., \& Mulyana, E. H. (2020). Keterampilan Mengomunikasikan Anak Usia Dini. Jurnal PAUD Agapedia, 4(1), 50-70.

Dista, F. N. (2020). Manajemen Pendirian Taman Kanak-Kanak. 8(December 2019), 101-111.

Gina, F., Syarif, S. A., Nasir, N., \& Perdhana, T. S. (2020). Rancangan Kurikulum Pendidikan Anak Usia Dini (PAUD) Di Sekolah Binaan Pemerintah Kota Bekasi. Jurnal Pengabdian Kepada Masyarakat UBJ, 3(1), 67-72. https://doi.org/10.31599/jabdimas.v3i1.58

Haryono, M., \& Hadiwinarto. (2020). Kemampuan Guru Dalam Merancang Penilaian Pembelajaran Paud Di Gugus Mengkudu Bengkulu Tengah Mimpira Haryono 1) , Hadiwinarto 2). 0581, 30-40.

Juandi, A. (2019). Lingkup pendidikan sekolah. (106).

Khayya, K. (2020). Penyelenggaraan Pembelajaran Berbasis Alam Dalam Pengenalan Kecerdasan Naturalis Pada Anak ( Studi Deskriptif di PAUD Alam Ar-Ridho Semarang) SKRIPSI.

Nastita, R. (2019). Implementasi Pembelajaran Anak Usia Dini Di Ra Al-Ulya 3 Bandar Lampung. Journal of Chemical Information and Modeling, 53(9), 1689-1699.

Praticia, R., Kamala, I., \& Juliawati. (2019). Studi Tentang Kemampuan Guru Melakukan Penilaian Pembelajaran Paud Di Gugus Mangga Di Palangka Raya Rayne. 15(2), 48-63.

Rasmita, D. (2019). Upaya Meningkatan Kompetensi Guru Dalam Pelaksanaan Proses Pembelajaran Melalui Supervisi Akademik Di Sd Negeri 017 Pasir Emas. Jurnal PAJAR (Pendidikan Dan Pengajaran, 3, 2614-1337.

Salim, Jamiludin, Darnawati, Sitti Rahmaniar Abubakar, Nurhayati, \& Irawaty. (2020). Pelatihan Pengembangan Desain Instruksional untuk Meningkatkan Kemampuan Pedagogik Guru PAUD. JPKMI (Jurnal Pengabdian Kepada Masyarakat Indonesia), Vol.1(Issue.2), 95-105. Retrieved from https://doi.org/10.36596/jpkmi.v1i2.34

Sari, K. M. (2020). Kompetensi Pedagogik Guru Paud Dalam Melaksanakan Penilaian Pembelajaran Anak Usia Dini Di Taman Kanak-Kanak Al-Muttaqin Sungai Duren Tesis. Buku Pedoman Penulisan Karya Ilmiah Cet. I, 1-92. Retrieved from http://scholar.google.com/scholar?hl=en\&btnG=Search\&q=intitle:UNIVERSITAS+ISLA M+NEGERI+MALANG+Malang\#2

Sujana, I. W. C. (2019). Fungsi Dan Tujuan Pendidikan Indonesia. (April), 29-39. 